\title{
PERIPHERAL VASCULAR AND CARDIAC EFFECTS OF NITROUS OXIDE IN THE BOVINE
}

\author{
Judd K. Lunn, Wen-Shin Liu, Theodore H. Stanley, Scott Gentry, ANd \\ JoHN B. ENGLISH
}

Despite ITS WIDE USE, there is a paucity of data concerning the effects of nitrous oxide alone on the heart and peripheral vascular system. This is especially true with regard to the influence of the gas on the intact, innervated, unanaesthetized cardiovascular system. Indeed, there are no reports of dose-response effects of nitrous oxide on cardiovascular dynamics in unintubated, unanaesthetized man or animals, and what data are available studying one or two concentrations of the agent are controversial. Thus, while some reports indicate that nitrous oxide does depress myocardial contractility, ${ }^{1-i}$ others do not.,5 Similarly, depression, stimulation and no change in haemodynamics have all been reported in studies employing a variety of concentrations of the gas in unanaesthetized and quasi-unanaesthetized dogs and man. ${ }^{1-5}$ Reasons for these different results are not entirely clear but are probably related to: a variety of experimental protocols; the relative impotency of nitrous oxide and, therefore, absence of dramatic cardiovascular changes with its employment under most circumstances; ease of modifying subtle cardiovascular changes produced by the gas with simultaneous use of other anaesthetics, intubation or positive pressure respiration; difficulty in studying impotent inhalation anaesthetics in animal preparations; and the necessity of using invasive techniques to measure adequately the subtle changes produced by the gas in man.

A number of recent reports from this laboratory $y^{6,7}$ have demonstrated the value of the bovine artificial heart (AH) model in investigations of cardiovascularly active pharmacological compounds. Besides docility and ease of handling and intrumentation, this model enables investigation of drug action in animals under no pharmacological or physiological influence such as anaesthesia, upper airway intubation or artificial respiration, which could modify the cardiovascular manifestations of the compound under investigation. In addition and equally important, utilization of an animal before and after implantation of an artificial heart for anaesthetic investigation allows quantitation and separation of the effects of the anaesthetic on the pheripheral vascular system after $\mathrm{AH}$ replacement from its effects on the heart plus the peripheral vascular system before $\mathrm{AH}$ replacement. In this study the bovine $\mathrm{AH}$ model was used to investigate and differentiate the cardiac and systemic vascular actions of increasing concentrations of nitrous oxide.

From the Departments of Anesthesiology and Surgery, the University of Utah College of Medicine, 50 North Medical Drive, Salt Lake City, Utah, 84132.

Please direct all correspondence to Dr. T.H. Stanley, Department of Anesthesiology, University of Utah College of Medicine, 50 North Medical Drive, Salt Lake City, Utah, 84132.

Presented in part at the 1976 annual meeting of the American Society of Anesthesiologists, San Francisco, California, October, 1976. 


\section{METHODS}

The experimental subjects were 15 unanaesthetized 85 to $104 \mathrm{~kg}$ bull calves. After anaesthetic induction with 3 to $5 \mathrm{mg} / \mathrm{kg}$ of intravenous sodium methohexital, intubation and maintenance of anaesthesia with intermittent doses of ketamine 2 to $3 \mathrm{mg} / \mathrm{kg}$ and doses of succinylcholine $0.5 \mathrm{mg} / \mathrm{kg}$ intravenously, each animal had a 10-gauge needle placed percutaneously into the right external jugular vein. With continuous pressure recording, a 7 Fr Swan-Ganz triple lumen catheter was threaded through the needle, through the right ventricle and into the proximal pulmonary artery (PA). Another catheter ( $14 \mathrm{Fr}$ ) was placed percutaneously into the opposite jugular vein and threaded into the right atrium. Following this, a small neck incision was made and a third catheter $(17 \mathrm{Fr}$ ) threaded down the right or left common carotid artery into the central aorta. Catheter position was documented by continuous pressure recording and catheter patency was maintained with a dilute heparinized $(2$ units $/ \mathrm{ml}$ ) lactated Ringer's solution which was administered at a rate of 1 to $2 \mathrm{ml} / \mathrm{hr}$ by a constant infusion pump. Anaesthesia was then terminated and the animal extubated and allowed to recover for 24 to 48 hours.

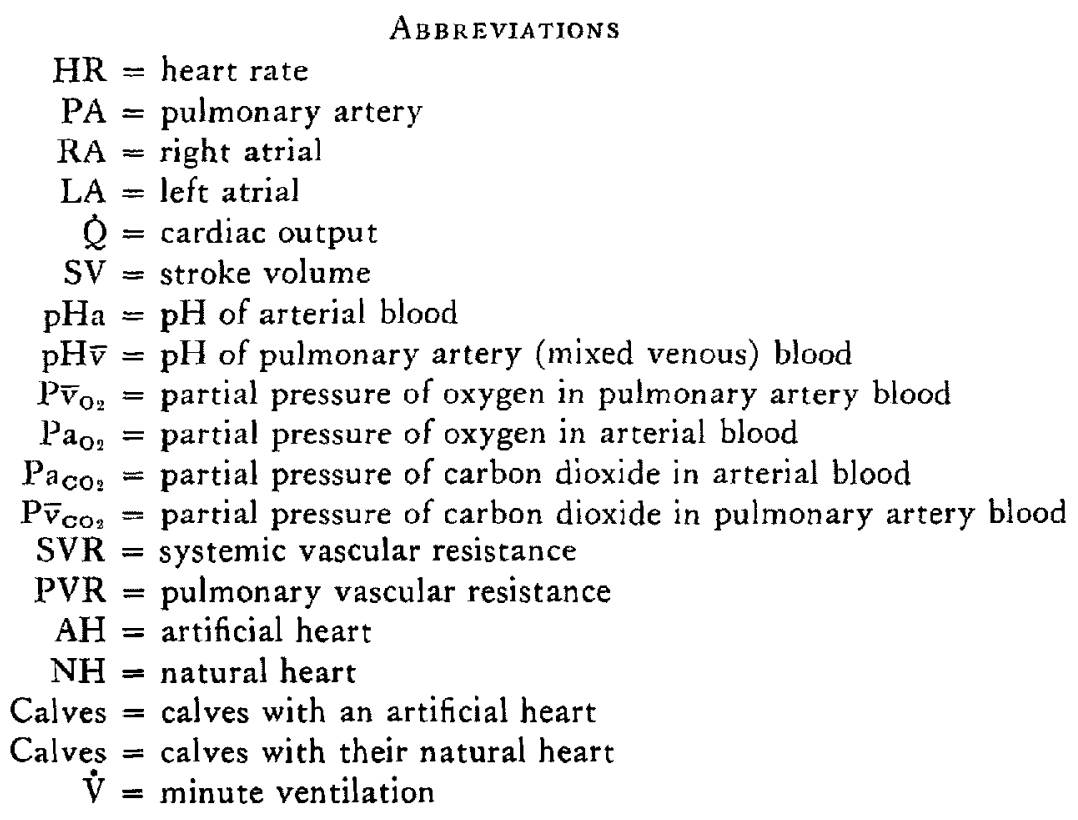

\section{Study procedures before artificial heart implantation}

Study procedures before artificial heart (AH) implantation were accomplished with the calves lying down, restrained with ropes in a metal calf cage, and breathing through a special calf face mask. In ten calves a Wright Spirometer was attached to the inspiratory portal of the face mask allowing minute ventilation $(\dot{V})$ to be measured. Aortic and pulmonary artery (PA) blood samples were drawn 
for blood gas (oxygen and carbon dioxide tension) analysis and $\mathrm{pH}$ and haemoglobin determinations while the calves were breathing room air. Heart rate (HR), mean aortic, PA and right atrial (RA) blood pressures and $\dot{V}$ were then recorded and a dye dilution cardiac output ( $\dot{\mathrm{Q}} \mathbf{T}$ ) determination was made using indocyanine green dye and a Waters Instruments, Inc. DCR-702 cardiac output computer system. Following this, the animals were allowed to breathe 100 per cent oxygen for 20 minutes. The face mask was attached to a standard 5-litre semi-closed anaesthesia circle system equipped with soda-lime carbon dioxide absorption canisters, a Wright spirometer, and one-way breathing valves. Inspiratory gases were delivered to the circle system at the rate of $10 \mathrm{~J} / \mathrm{min}$ from recently calibrated Ohio rotameter flowmeters. After a 20 -minute equilibration period with 100 per cent oxygen, aortic and PA blood samples were drawn for blood gas and $\mathrm{pH}$ analysis, HR and aortic, PA and RA blood pressures were again recorded, $\dot{V}$ re-measured and $\dot{Q} \mathrm{~T}$ re-determined. After this, the calves were given 10 per cent nitrous oxide in oxygen and after 20 minutes the data were again collected. Nitrous oxide was then increased to 20 per cent and after 20 minutes the data were collected again. In a similar fashion data were collected after $30,40,50,60$, and 70 per cent nitrous oxide and then again following breathing 100 per cent oxygen for 20 minutes.

Blood carbon dioxide tension was measured with a Severinghaus electrode, $\mathrm{pH}$ with a Radiometer glass electrode and oxygen tension with a modified Clark electrode. All electrodes were maintained at $39^{\circ} \mathrm{C}$ (normal body temperature for a calf) and frequently re-calibrated with standard solutions and gases of known concentration and tension.

Systemic vascular resistance (SVR) in dynes $-\mathrm{sec} / \mathrm{cm}^{-5}$ was calculated from the following equation:

$$
\text { SVR }=\frac{\text { mean aortic pressure }- \text { mean RA pressure }}{\dot{Q}_{\mathrm{R}}} \times 80
$$

Stroke volume (SV) was calculated by dividing $\dot{\mathrm{Q}} \mathbf{T}$ by $\mathrm{HR}$.

Two to four days later each calf had its natural heart (NH) replaced with a pneumatically driven $\mathrm{AH}$.

\section{Design of the artificial heart and the artificial heart driving system}

A silicone rubber (Silastic) ${ }^{\circ}$ or polyurethane-elliptical type of $\mathrm{AH}$ was used in these investigations. This type of $\mathrm{AH}$ has been previously described.$^{8-12}$ It is composed of four chambers (two artificial atria and two artificial ventricles), contains four Bjork-Shiley pyrolytic carbon disc valves and weighs approximately $300 \mathrm{~g}$. Each ventricle consists of a rigid outer casing and a pliable inner bloodcontaining chamber between which compressed air is applied for compression and ejection of blood.

An intrinsic systern of AH control based on the maintenance of relatively normal atrial pressures was used in all the experiments. This type of control system has been previously described. ${ }^{8}$ Basically, it consists of two direct-acting three-way solenoid

${ }^{\circ}$ Silastic, silicone rubber of the Dow-Corning Company of Midland, Mich. 
valves, located in the control module, which apply compressed air through the two air drive lines during systole and exhaust air to the atmosphere during diastole. The two air-drive lines bring compressed air from the control module (standing next to the calves' cage) through the calves' chest wall to the AH ventricles within the calves' chest. With this system the rate of filling and, therefore, the volume of blood entering each ventricle during the diastolic period increases with an increase in atrial pressure. This volume is expelled during the next ventricular systole. As filling of the ventricle diminishes, so does stroke volume. There is thus an inherent balance between the pulmonic and systemic circulatory systems, as with the natural heart, and extremes of high and low atrial and venous pressures are avoided. The $\mathrm{AH}$ also responds, as does the NH, to increases and decreases in systemic vascular resistance with appropriate decreases or increases in ventricular stroke volume and cardiac output.

\section{Protocol and study procedures after artificial heart implantation}

Artificial heart implantation was accomplished through a right lateral thoracotomy as has been previously described." Post-AH implantation studies ivere initiated 6 to 9 days after operation when tidal volume was $>400 \mathrm{ml}, \mathrm{Para}_{2}<40$ torr and $\mathrm{Pa}_{\mathrm{O}_{2}}>60$ torr for six or more hours while breathing room air. Additional criteria for acceptance in the study included mean aortic, PA and RA pressures within 20 per cent of pre-AH. levels when $\mathrm{AH}$ output was adjusted (by $\mathrm{AH}$ rate changes) to approximate pre-implantation values. When these requirements were met, and with the animals lying in the metal calf cage, pre-AH implantation study procedures were repeated.

Mean LA pressure was an additional parameter available for measurement after $\mathrm{AH}$ implantation. The latter was obtained, as were RA, PA and aortic pressures and blood samples, from high pressure tubing connected to taps on the artificial atria and vascular grafts attaching the artificial ventricles to the natural PA and aorta. With LA pressure it was possible to calculate pulmonary vascular resistance (PVR) in dynes-sec/ $\mathrm{cm}^{-5}$ after $\mathrm{AH}$ implantation using the following equation:

$$
\text { PVR }=\frac{\text { mean PA pressure }- \text { mean LA pressure }}{\bar{Q}_{\mathbf{T}}} \times 80
$$

Changes in all variables with nitrous oxide were compared to room air and 100 per cent oxygen using Student's paired t-test. Comparison of variables in NH and AH groups at a given concentration were made using Student's unpaired $t$-test. $P<0.05$ was considered statistically significant.

\section{Results}

Mean values of aortic and $\mathrm{PA}, \mathrm{Po}_{2}, \mathrm{Pco}_{2}$ and $\mathrm{pH}$ during the entire study appear in Tables I and II. Aortic and $\mathrm{PA}, \mathrm{PO}_{2}, \mathrm{PCO}_{2}$ and $\mathrm{pH}$ were not significantly different in $\mathrm{NH}$ and $\mathrm{AH}$ calves during similar situations throughout the study. "Breathing

${ }^{\circ}$ Utilizing Student's unpaired t-test. 


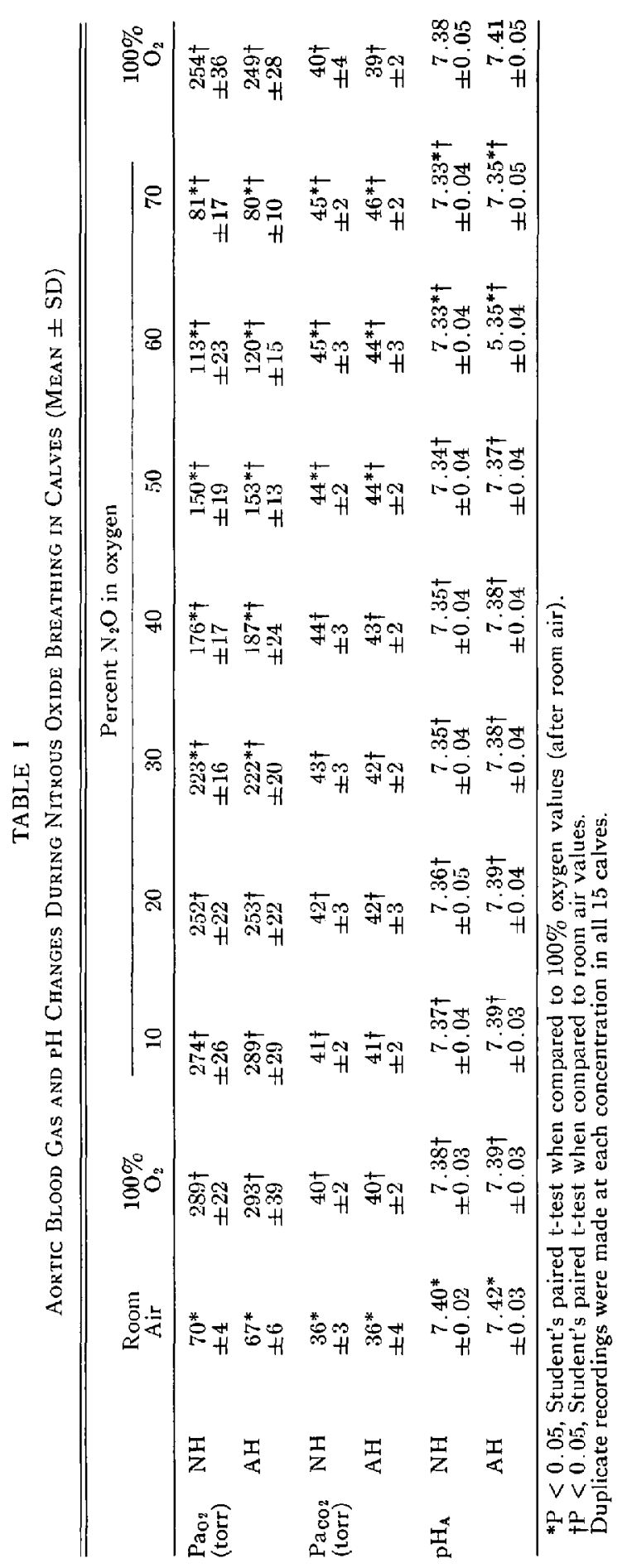




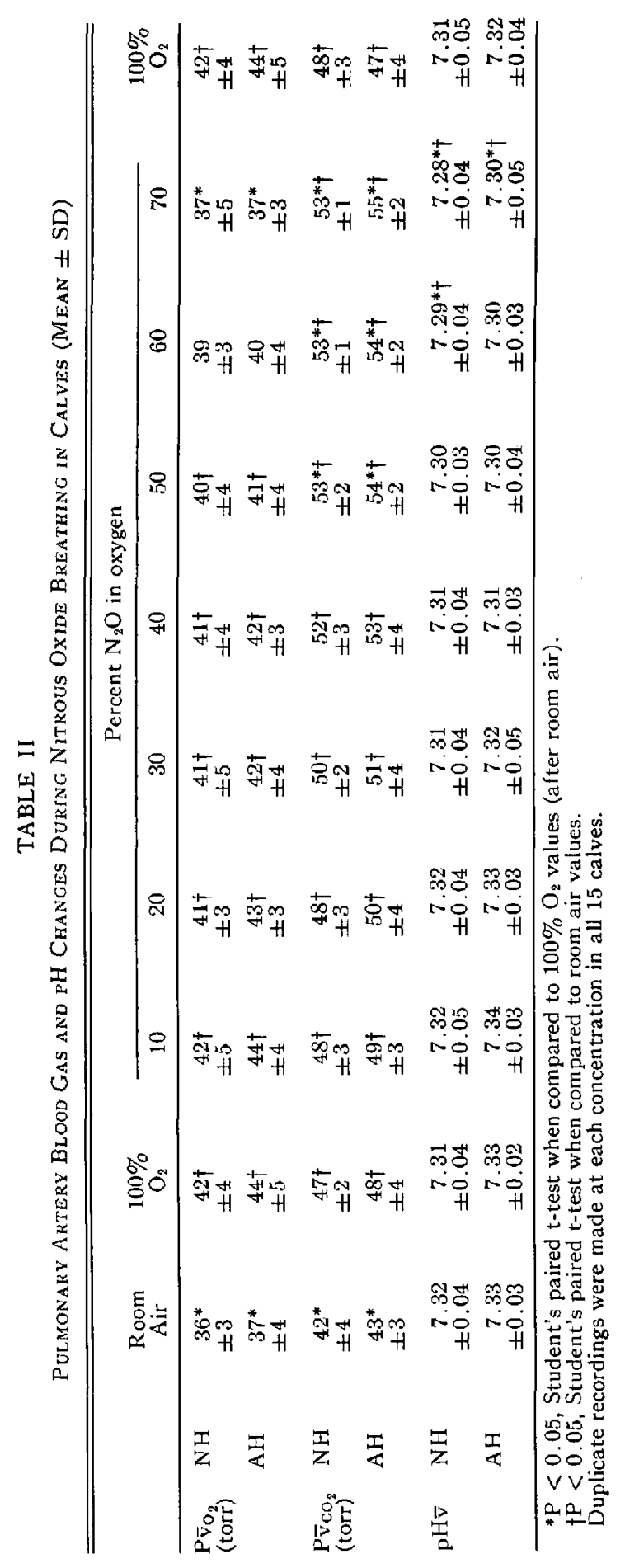




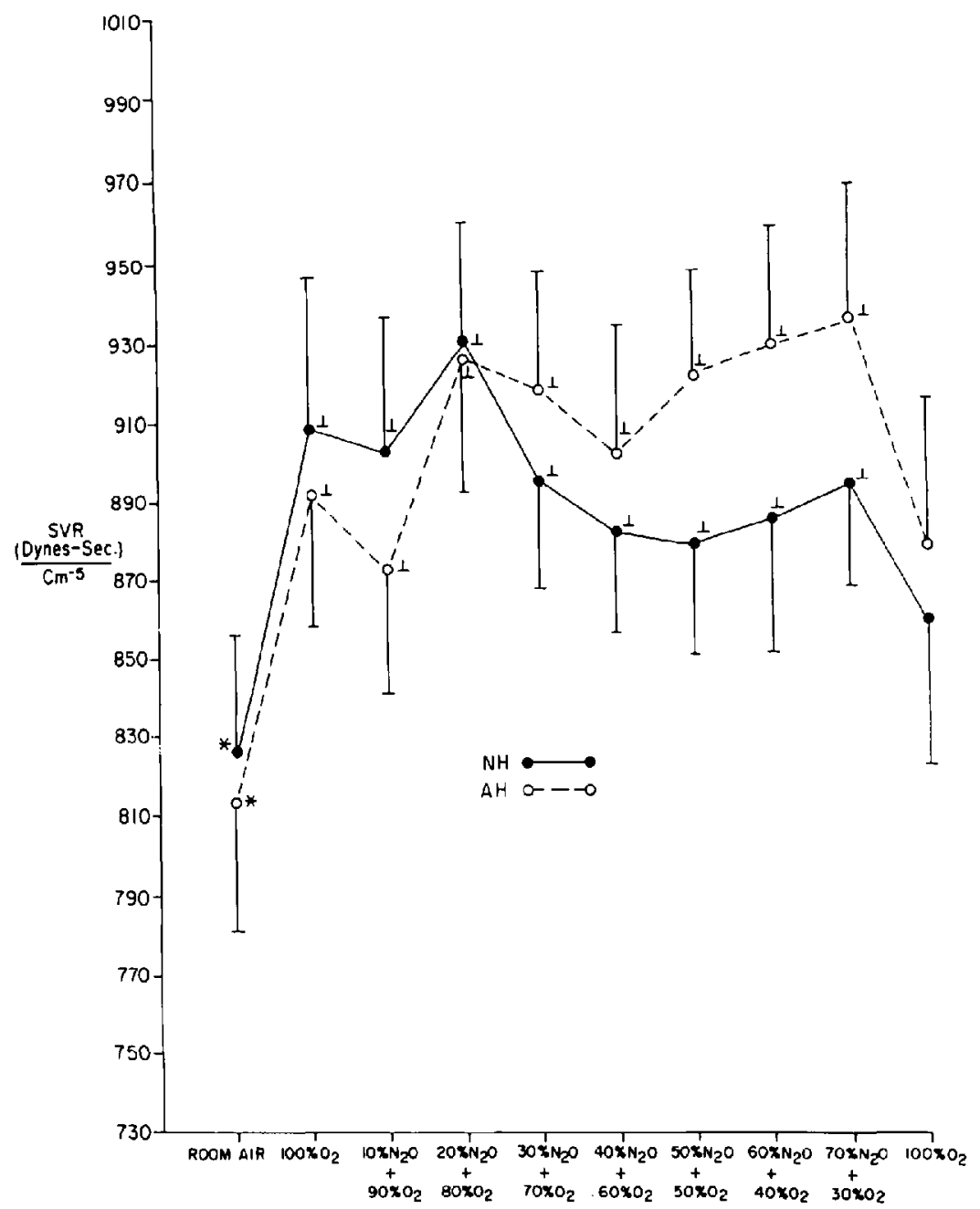

FIGURE 1. Systemic vascular resistance (mean \pm SD) during room air breathing, following 100 per cent oxygen and then increasing concentrations of nitrous oxide in oxygen. Duplicate measurements were made at each concentration in all 15 calves. $\perp P<0.05$, Student's paired t-test when compared to room air. ${ }^{*} \mathbf{P}<0.05$, Student's paired $t$-test when compared to 100 per cent oxygen (after room air).

100 per cent oxygen did not significantly alter pulmonary artery $\mathrm{pH}(\mathrm{pH} \overline{\mathrm{v}}$ in $\mathrm{NH}$ or $\mathrm{AH}$ calves but did depress, $\mathrm{P}<0.05$, aortic $\mathrm{pH}(\mathrm{pHa})$ and increase $\mathrm{Pa}_{\mathrm{O}_{2}}$ and $\mathrm{P} \overline{\mathrm{v}}_{\mathrm{CO}}$ in both groups of animals. When compared to 100 per cent oxygen breathing nitrous oxide decreased $\mathrm{Pa}_{\mathrm{O}_{2}}$ (first significant, $\mathrm{P}<0.05$, at 30 per cent), $\mathrm{pHa}$ and pHv (significant at 60 per cent) and increased $\mathrm{Pa}_{\mathrm{CO}_{2}}$ and $\mathrm{P}_{\mathrm{V}_{2}}$ (first significant at 50 per cent) in $\mathrm{NH}$ and $\mathrm{AH}$ calves. Repeat 100 per cent oxygen breathing resulted in a return of aortic and PA blood gases and $\mathrm{pH}$ to values similar to those obtained immediately before breathing nitrous oxide in both groups of animals.

$\mathrm{NH}$ and $\mathrm{AH}$ calves sustained significant, $\mathrm{P}<0.05$, and similar increases in SVR (Figure 1) and decreases in PA pressure and $\dot{Q}_{\mathbf{T}}$ (Figures 2 and 3) upon breathing 


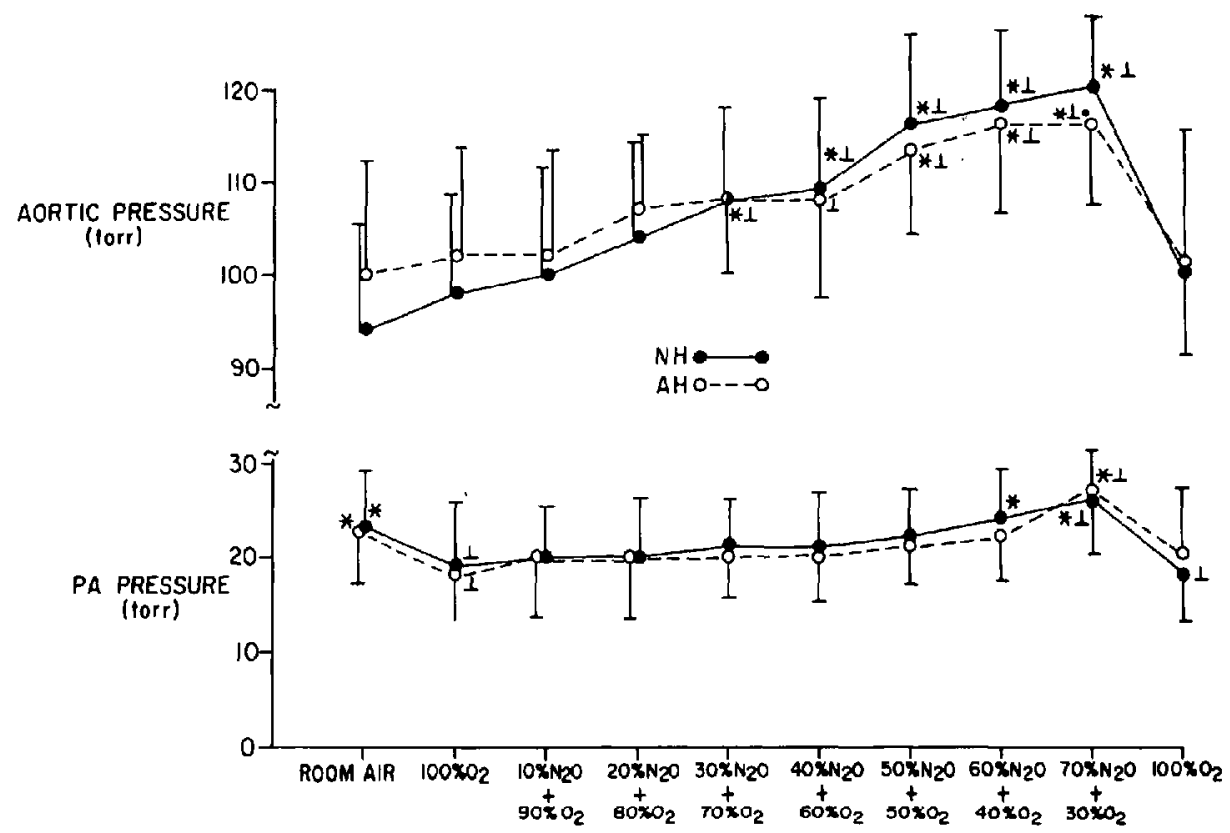

Figune 2. Mean aortic and pulmonary artery blood pressure (mean \pm SD) during roon air breathing, following 100 per cent oxygen and then increasing concentrations of nitrous oxide in oxygen. iP $<0.05$, Student's paired $t$-test when compared to room air, " $\mathrm{P}<0.05$, Student's paired $t$-test when compared to 100 per cent oxygen (after room air) $P<0.05$, Student's unpaired t-test when compared to changes from 100 per cent oxygen (after room air) at the rame concentration of nitrous oxide in NH calves.

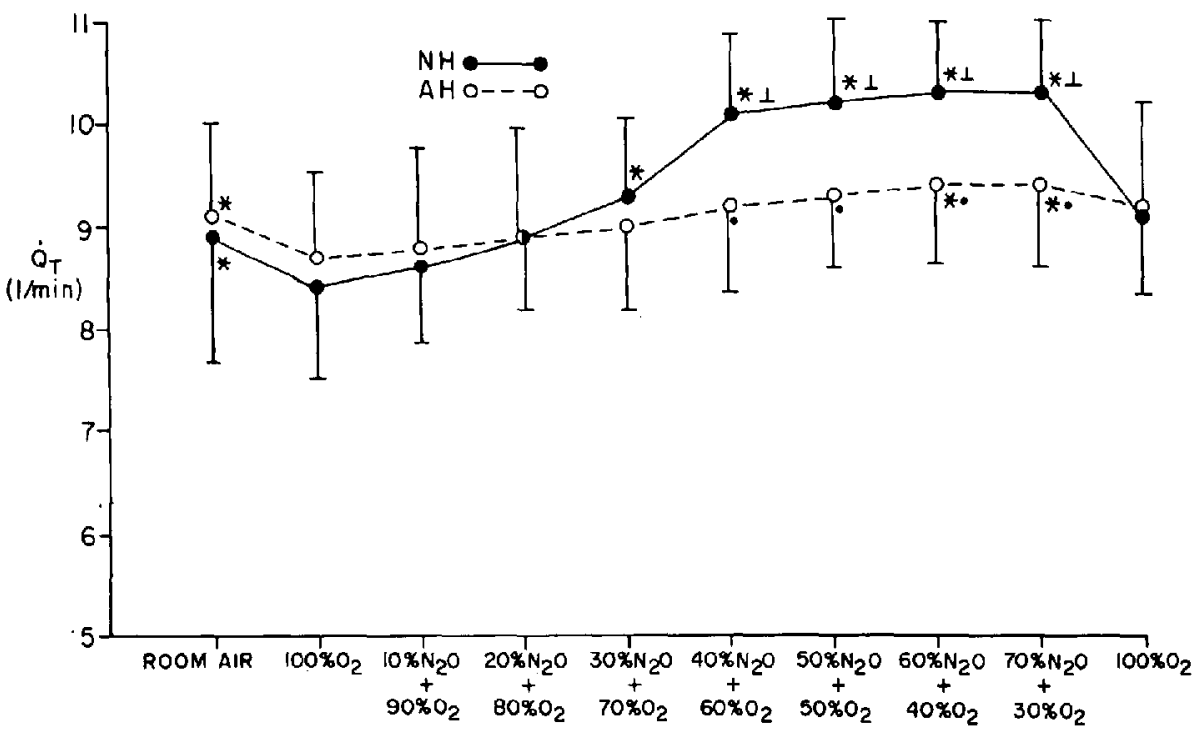

Figure 3. Cardiac output (mean $\pm \mathrm{SD}$ ) during room air breathing, following 100 per cent oxygen and then increasing concentrations of nitrous oxide in oxygen. Symbols are the same as in Figure 2. 


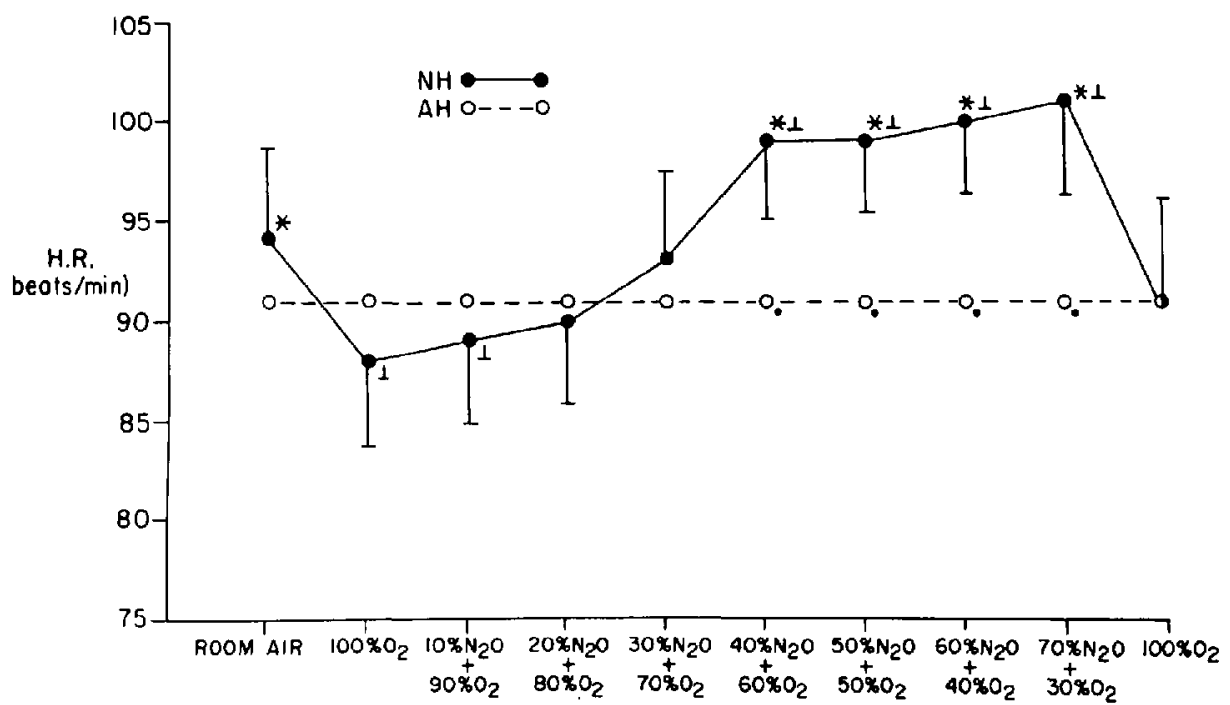

Ficure 4. Heart rate (mean \pm SD) during room air breathing, following 100 per cent oxygen and then increasing concentrations of nitrous oxide in oxygen. Symbols are the same as in Figure 2.

100 per cent oxygen. Breathing oxygen did not significantly alter mean aortic or RA pressures (Figures 2 and 7 ) in either group of animals or mean LA pressure (Figure 7) in AH calves or SV (Figure 5) in NH calves. NH calves sustained a significant, $\mathrm{P}<0.05$, decrease in HR (Figure 4) while AH calves experienced a significant, reduction in SV and PVR (Figures 5 and 6) during pure oxygen breathing (PVR and LA pressure could not be measured in NH calves and HR was

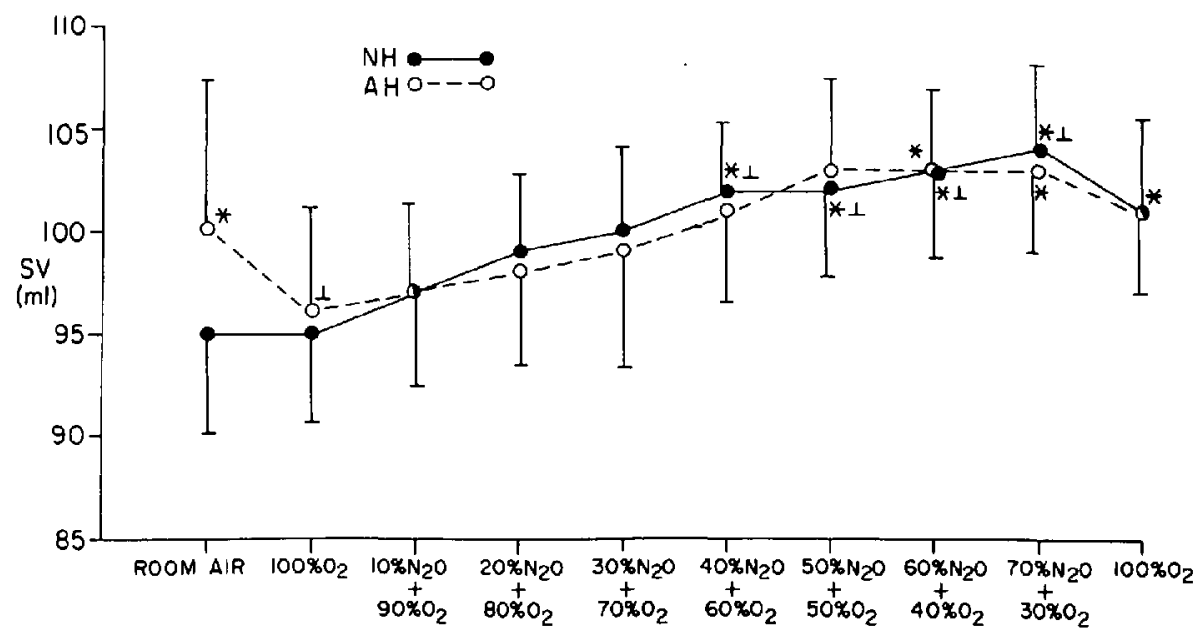

Ficure 5. Stroke volume (mean $\pm S D$ ) during room air breathing following 100 per cent oxygen and then increasing concentrations of nitrous oxide in oxygen. Symbols are the same as in Figure 2. 


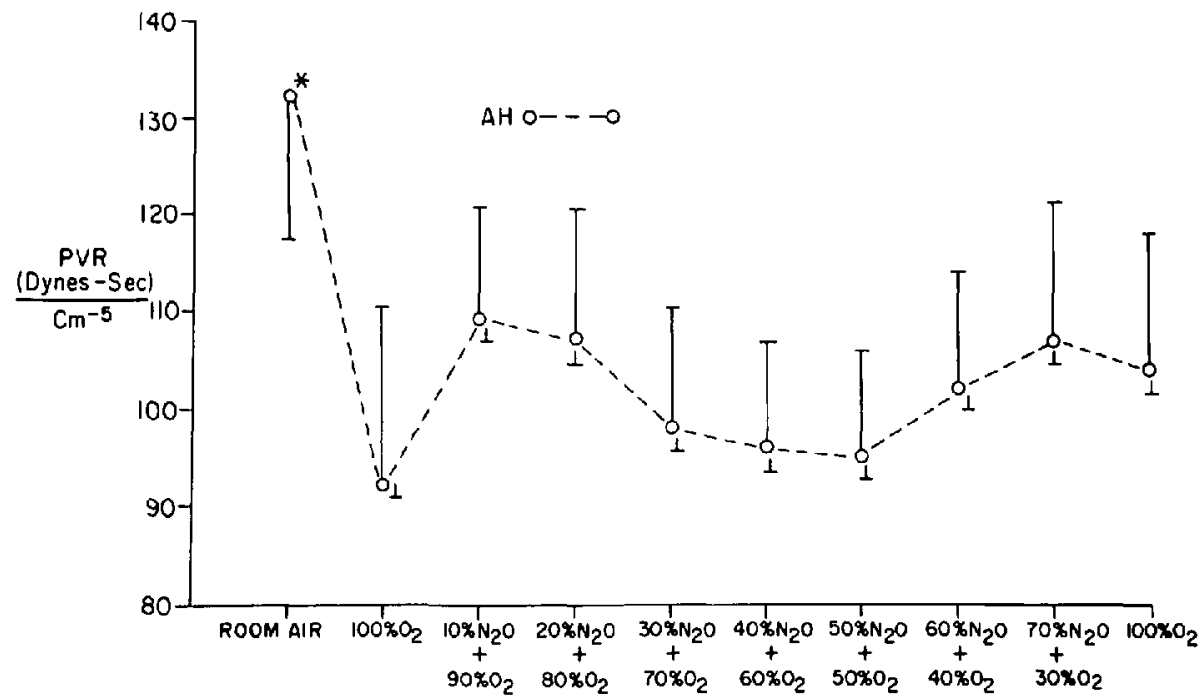

Ficure 6. Pulmonary vascular resistance (mean $\pm \mathrm{SD}$ ) during room air breathing following 100 per cent oxygen and then increasing concentrations of nitrous oxide. Symbols are the same as in Figure 2.

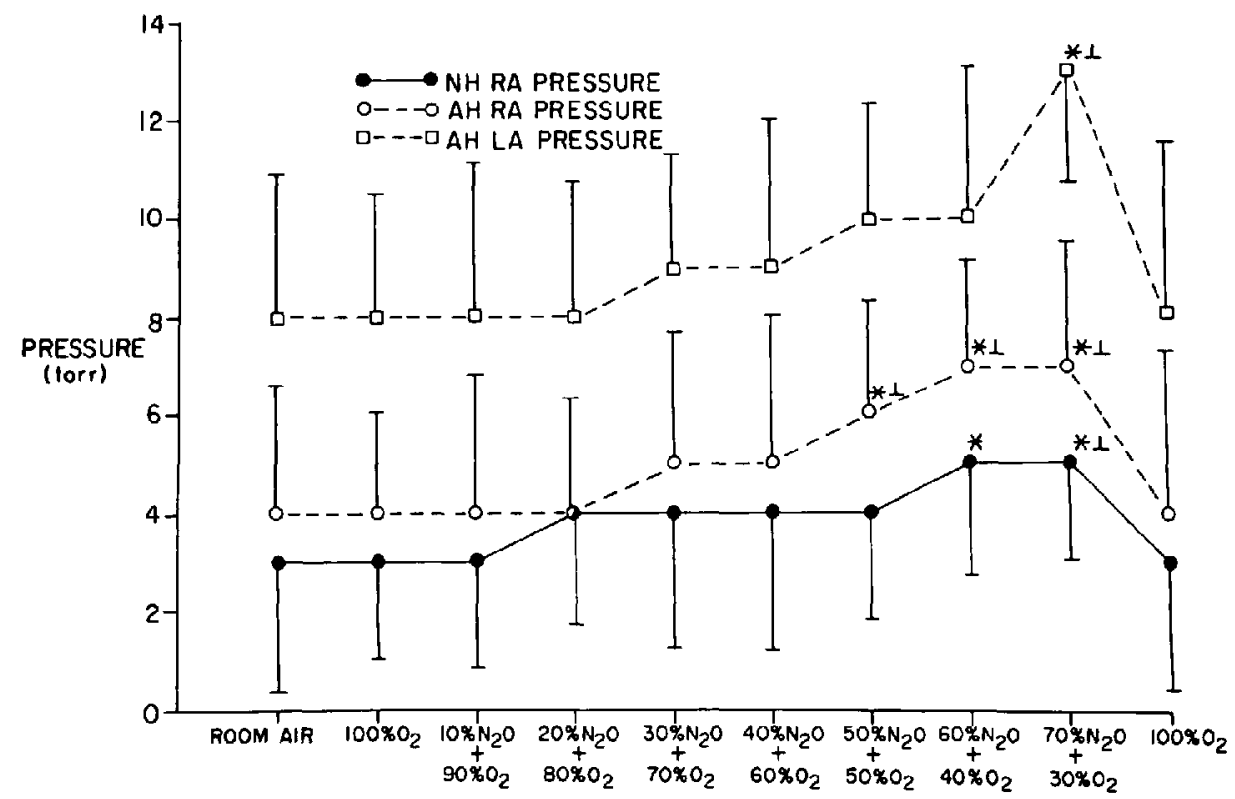

Frcure 7. Mean right and left atrial pressures (mean \pm SD) during room air breathing, following 100 per cent oxygen and then increasing concentrations of nitrous oxide. Symbols are the same as in Figure 2. 


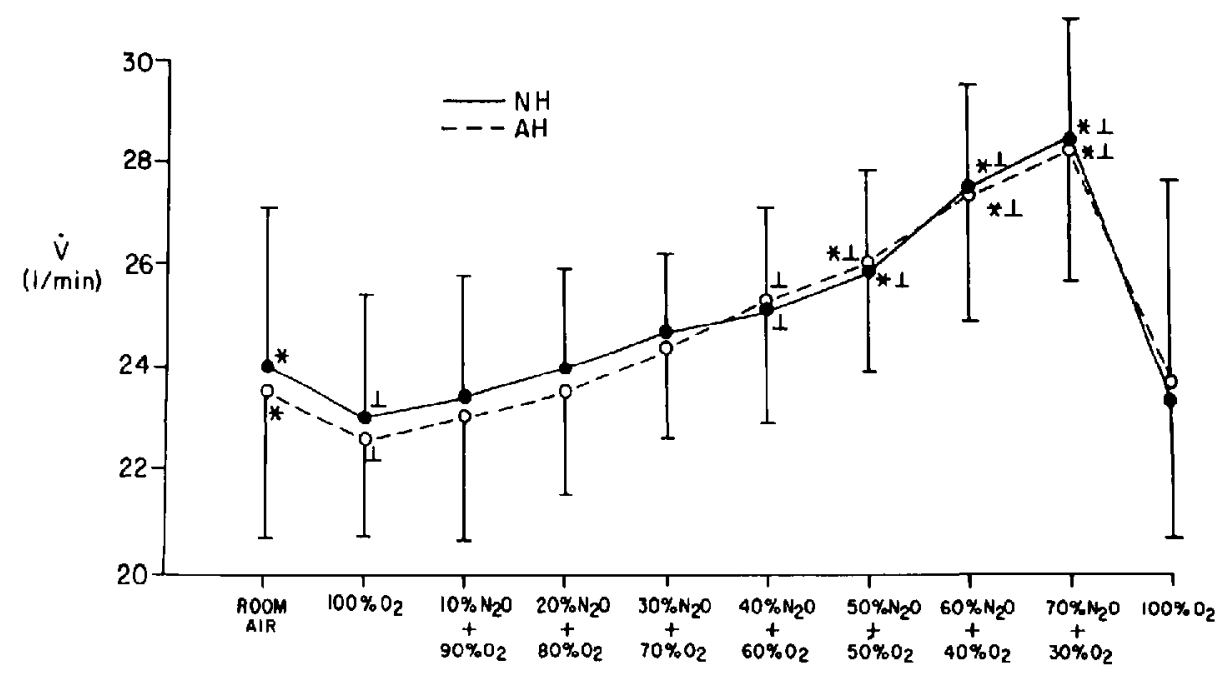

Ficure 8. Minute ventilation (mean $=\mathrm{SD}$ ) during room air breathing, following 100 per cent oxygen and then increasing concentrations of nitrous oxide. Symbols are the same as in Figure 2. Recordings of this variable were only made in ten calves.

fixed in $\mathrm{NH}$ animals). $\dot{\mathrm{V}}$ was slightly decreased during pure oxygen breathing in both $\mathrm{NH}$ and $\mathrm{AH}$ calves, Figure 8 .

Nitrous oxide significantly increased $\dot{V}, \dot{Q}$ T, SV and mean aortic, PA and RA pressures in both NH and AH calves but did not significantly change SVR. Heart rate was increased in $\mathrm{NH}$ animals but, as mentioned above, was fixed in $\mathrm{AH}$ animals. AH calves experienced an increase in LA pressure during nitrous oxide breathing but no change in PVR at any concentration of nitrous oxide. Elevations in HR and $\dot{\mathrm{Q}} \mathrm{T}$ at nitrous oxide concentrations $>30$ per cent and aortic pressure at 70 per cent nitrous oxide were significantly greater in NH than AH animals $(\mathrm{P}<0.05)$.

In both groups of animals repeat 100 per cent oxygen breathing resulted in a return of all cardiovascular variables, with the exception of SV in NH calves, to values not significantly different from those obtained immediately prior to nitrous oxide breathing

\section{Discussion}

The findings of this study using the bovine AH model, demonstrate that increasing concentrations of nitrous oxide produced significant increases in $\dot{V}, \mathrm{SV}$, HR, $\dot{Q} \mathrm{~T}$ and aortic, RA and pulmonary artery blood pressure in unanaesthetized, spontaneously breathing $\mathrm{NH}$ calves. These changes, although generally less marked, also occur when $\mathrm{AH}$ calves breathe nitrous oxide and are accompanied, as they are in NH calves, by small increases in arterial and mixed venous Pco. and decreases in $\mathrm{pH}$. Our results suggest, therefore, that high concentrations of nitrous oxide produce significant cardiovascular stimulation when employed as the sole anaesthetic in spontaneously breathing animals. Finally, the data demonstrate 
that nitrous-oxide-induced cardiovascular stimulation is secondary to both improved venous return to the heart, i.e. a Frank Starling effect, as well as increased myocardial chronotropy.

Cardiovascular stimulation, as manifested by elevations in HR, arterial and venous blood pressures, SVR, SV or Q், have, as mentioned previously, been described by some authors when nitrous oxide is breathed alone ${ }^{\tilde{5}}$ or when the gas is added to halothane-oxygen anaesthesia. ${ }^{13,14}$ These changes, when observed, have usually been attributed to increased sympathetic activity. Eisle and Smith ${ }^{2}$ found that 40 per cent nitrous oxide tended to increase plasma norepinephrine and, occasionally, epinephrine in unanaesthetized supine man. Smith and co-workers ${ }^{13}$ demonstrated even greater elevations in plasma norepinephrine when 70 per cent nitrous oxide was administered to volunteers equilibrated with 1.5 to 2.0 per cent halothane and oxygen.

It is not entirely clear how nitrous oxide increases sympathetic activity. Proposed mechanisms have included increased rate of catecholamine synthesis; blockade of active transport from extracellular fluid to the cytoplasmic mobile pool, causing augmentation of norepinephrine from the cytoplasmic mobile pool, leading to a sympathomimetic effect (tyramine-like effect); inhibition of catechol-omethyl transferase or active release from the intragranular mobile pool (guanethidine-like effect). ${ }^{13}$ There is also evidence that it is not nitrous oxide but rather decreases in oxygen which are responsible for sympathetic stimulation. ${ }^{13.15}$ The present study does not establish which one or combination of these mechanisms applies. However, it does suggest that at least a component of the increased sympathetic stimulation that occurs during nitrous oxide administration may be due to concomitant increases in $\mathrm{Pa}_{\left(0_{1}\right.}$ and/or $\mathrm{Pv}_{\mathrm{CO}_{2}}$. An increase in $\mathrm{Pa}_{\mathrm{CO}}$ may be explained by nitrous-oxide-induced respiratory depression. However, minute ventilation was increased by nitrous oxide in this study and returned to values not significantly different from room air or 100 per cent oxygen controls, with return to breathing pure oxygen. Indeed, respiratory depression has never been reported with clinical concentrations ( 10 to 70 per cent) of nitrous oxide in oxygen. Hombein, et al. found that 70 per cent nitrous oxide also produced a small increase in minute ventilation when added to volunteers equilibrated with halothane $(0.8$ per cent) in oxygen.

We are unaware of any previous study in which $P \bar{v}_{\mathrm{CO}}$ was measured before and during administration of nitrous oxide. However, increases in $\mathrm{Pa}_{\mathrm{CO}}$ have been described with nitrous oxide anaesthesia when the gas has been used without other inhalation anaesthetics as well as when it has been added to halothaneoxygen anaesthesia. ${ }^{13,14,16}$ Possible explanations for increases in $\mathrm{Pa}_{\mathrm{CO}}$ upon addition of nitrous oxide could include the second gas effect of nitrous oxide on alveolar $\mathrm{PcO}_{2}$, an increase in physiological dead space or that nitrous oxide produces enough sympathetic stimulation to increase $\mathrm{P}_{\mathrm{v}_{\mathrm{CO}}}$ more than the simultaneous increase in $V$ can compensate for. The concentration effect of nitrous oxide on a second alveolar gas should only persist for a short time. Even though nitrous oxide concentration was increased by 10 per cent every 20 minutes it is doubtful that this mechanism could adequately explain the 5 to 6 torr average increase in $\mathrm{Paco}_{2}$ measured at 70 per cent nitrous oxide when compared to 100 per cent oxygen. 
This leaves nitrous-oxide-induced increases in physiological dead space, increases in plasma catecholamines or both as the most likely causes of the increased $\mathrm{Pa}_{\mathrm{CO}_{2}}$ observed. Unfortunately neither physiological dead space nor plasma catecholamines were measured during this study.

An interesting finding of this investigation was the significant depression in $\dot{Q} \mathrm{~T}$ and increase in SVR which breathing 100 per cent oxygen produced in both NH and $\mathrm{AH}$ calves. These alterations have also been reported in man with oxygen. ${ }^{17}$ While the mechanism causing these changes is not entirely understood, it has been suggested that a significant component of the reduction in $\dot{Q} \mathrm{~T}$ is due to oxygeninduced metabolic depression of cardiac muscle. ${ }^{17}$ Similar reductions in Q $\mathrm{T}$ in $\mathrm{NH}$ and AH calves with 100 per cent oxygen breathing in this study, while not completely negating metabolic depression of cardiac muscle as a mechanism, suggest it is not a major explanation of the findings.

Alterations in QT after pharmacological administration in NH calves are dependent on changes in pre-load, after-load and the chronotropic and inotropic state of the heart. AH calves respond in a similar fashion except their chronotropic and inotropic states are fixed. Since nitrous oxide breathing produced no significant change in SVR and PVR in NH or AH calves at any time in this study, the significant difference in $\dot{Q} \mathrm{~T}$ (with 40 to 70 per cent nitrous oxide breathing) between $\mathrm{NH}$ and $\mathrm{AH}$ calves can only be cxplained by alterations in pre-load or myocardial inotropy and/or chronotropy. The response of $A H$ hearts to changes in venous return (pre-load) is similar to that of $\mathrm{NH}$ hearts. Therefore, the difference in $\dot{Q}_{\mathbf{r}}$ between the two groups of animals during nitrous oxide breathing must be due to direct or induced myocardial effects of breathing the gas. Nitrous oxide produced similar increases in stroke volume in $\mathrm{NH}$ and $\mathrm{AH}$ calves $(+9$ per cent and +7 per cent respectively at 70 per cent when compared to 100 per cent oxygen values) indicating that increased venous return is one mechanism by which the gas improves QT. However, nitrous oxide also increased HR 13 per cent in $\mathrm{NH}$ calves. The latter change represents the majority of the difference in $\dot{Q}^{\mathrm{T}}$ between $\mathrm{NH}$ calves and $\mathrm{AH}$ calves that have a fixed HR. This suggests that nitrous oxide, or the consequence of breathing it, produces significant chronotropic stimulation. Since high ( 50 to 75 per cent) concentrations of nitrous oxide as well as 100 per cent oxygen have been shown to have little direct effect on myocardial chronotropy or inotropy in isolated myocardial tissue preparations, ${ }^{11}$ these data, while not exactly elucidating the mechanism, provide additional support for the concept of indirect myocardial stimulation during nitrous oxide anaesthesia.

\section{SUMMARY}

Peripheral vascular and myocardial effects of increasing concentrations of nitrous oxide ( 0 to 70 per cent) in oxygen were determined in 15 unanaesthetized calves before and after replacement of their natural heart $(\mathrm{NH})$ with a pneumatically driven artificial heart (AH). Nitrous oxide produced concentration-related decreases in arterial and mixed venous $\mathrm{pH}$ and increases in minute ventilation and arterial and mixed venous carbon dioxide tensions in both $\mathrm{NH}$ and $\mathrm{AH}$ calves. Nitrous oxide resulted in significant increases in cardiac output, stroke volume 
and mean aortic, pulmonary artery and right atrial pressures in $\mathrm{NH}$ and $\mathrm{AH}$ calves, but did not significantly change systemic vascular resistance in either group of animals. Heart rate was increased in NH calves but was fixed in AH calves. Elevations in heart rate and cardiac output at nitrous oxide concentrations greater than 30 per cent and aortic pressure at 70 per cent nitrous oxide were significantly greater in $\mathrm{NH}$ than $\mathrm{AH}$ animals $(\mathrm{P}<0.05)$. These data demonstrate that nitrous oxide stimulates the cardiovascular system in spontaneously breathing mammals and that the changes result from improved venous return and an increase in myocardial chronotropy. Our findings also suggest that cardiovascular stimulation during nitrous oxide breathing may be related to increased concentrations of arterial and/or venous carbon dioxide.

\section{RÉSUMÉ}

Nous avons étudié les effects cardiaques et vasculaires périphériques de concentrations croissantes de protoxyde d'azote (de 10 à 70 pour cent d'un mélange protoxyde-oxygène) chez le veau à l'état d'éveil. Cette étude a porté chez l'animal normal et chez l'animal porteur d'un cœur artificiel actionné par un système pneumatique. L'utilité d'une telle préparation animale pour l'étude des effets cardiovasculaires d'agents pharmacologiques a été démontrée dans des rapports récents émanant de notre laboratoire.

Nous avons observé chez 15 veaux soumis à cette étude, une augmentation des $\mathrm{PCO}_{2}$ artérielles et veineuses suite à l'inhalation de protoxyde d'azote, et ceci chez les animaux normaux et chez les animaux porteurs d'un cœur artificiel. L'inhaJation de protoxyde produisait de plus, tant chez l'animal normal que chez l'animal à cœur implanté, une augmentation du débit cardiaque, du volume d'éjection et des pressions moyennes au niveau de l'aorte, de l'artère pulmonaire et de l'oreillette droite; la résistance périphérique n'était pas modifiée. La fréquence cardiaque augmentait chez le veau normal et demeurait fixe chez le veau porteur de limplant. Les élévations de la fréquence et du débit cardiaques que l'on a observées aux concentrations de protoxyde supérieures à 30 pour cent et les élévations de la pression aortique survenant à des concentrations de 70 pour cent étaient significativement plus grandes chez les animaux à coeur normal.

Nos résultats démontrent que le protoxyde d'azote stimule le système cardiovasculaire chez les animaux en respiration spontanée et que les changements observés découlent d'une amélioration de retour veineux et d'une stimulation chronotrope. Nos résultats suggèrent de plus que la stimulation cardiovasculaire observée sous protoxyde d'azote est liée à l'élévation de la $\mathrm{PCo}_{2}$ artérielle et/ou veineuse.

\section{REFERENCES}

1. Eisele, J.H., Tnenchard, D., Stubbs, J., \& Guz, A. The immediate cardiac depression by anesthetics in conscious dogs. Brit. J. Anaesth. 41: 86 (1969).

2. Eisele, J.H. \& Sirth, N.T. Cardiovascular effects of 40 per cent nitrous oxide in man. Anesth. \& Analg. 5I: 956 ( 1972 ).

3. Craythonne, N.W.B. \& Dahby, T.D. The cardiovascular effects of nitrous oxide in the dog. Brit. J. Anaesth. 37: 560 (1965). 
4. Goldberg, A.H., Sohn, Y.Z., \& Phear, W.P.C. Direct myocardial effects of nitrous oxide. Anesthesiology 37: 373 (1972).

5. Smith, N.T. \& Conascio, A.N. The cardiovascular effects of nitrous oxide during halothane anaesthesia in the dog. Anesthesiology 27:560 (1966).

6. Liv, W.S., Stanley, T.H., Isern-Amaral, J., Ward, B., Lunn, J.K., Gentry, S., \& Alwood, $S$. Cardiovascular and respiratory effects of isoproterenol before and after artificial heart implantation. Anesth. \& Analg. 55: 560 ( 1976 ).

7. Stañey, T.H., Isern-Amaral, J., Liu, W.S. Peripheral vascular versus direct cardiac effects of calcium. Anesthesiology 45: 46 (1976).

8. Kwan-Gett, C.S., Wu, Y., Collan, R., Jacobsen, S., \& KolfF, W.J. Total replacement artificial heart and driving system with inherent regulation of cardiac output. Trans. Amer, Soc. Artif. Int. Organs 15: 245 (1969).

9. Stanley, T.H., Volder, J., \& KolfF, W.J. Extrinsic artificial heart control via mixed venous blood gas tension analysis. Trans. Amer. Soc. Artif. Int. Organs 19: 258 (1973).

10. Stanley, T.H. \& Oster, H. The pulmonary effects of changes in left ventricular contractility. Surg. Forum 25: 191 (1974).

11. Stanley, T.H., Liu, W.S., Isern-Amaral, J., Gentry, S., \& Kennard, J. Periodic pulmonary shunt analysis as a method of optimizing cardiac output after artificial heart implantation. Trans. Amer. Soc. Artif. Int. Organs 21: 353 (1975).

12. Lunn, I.K., Liu, W.S., Stanley, T.H., Gentry, S, Kolff, J. \& Olsen, D. Effects of treadmill exercise on cardiovascular and respiratory dynamics before and after artificial heart implantation. Trans. Amer. Soc. Artif. Int. Organs 22: 315 (1976).

13. Smith, N.T., Ecer, E.I., II, Stoeltine, R.K., WhaYne, T.F., Culles, D. \& Kadis, L.B. The cardiovascular and sympathomimetic responses to the addition of nitrous oxide to halothane in man. Anesthesiology 32:410 (1970).

14. Hornbein, T.F., Martin, W.E., Bonica, J.J., Freund, F.C., \& Parmentieh, P. Nitrous oxide effects on the circulatory and ventilatory responses to halothane. Anesthesiology 31 : 250 (1969).

15. Andensen, A. \& Hillestad, L. Hemodynamic responses to oxygen breathing and the effect of pharmacologic blockade. Acta. Med. Scand. 188: 419 (1970).

16. Kitahata, L.M., Taub, A., \& Conte, A.J. The effect of nitrous oxide on alveolar carbon dioxide tension. Anesthesiology 35: 607 (1971).

17. Andensen, A. \& Hillestad, L. Haemodynamic responses to oxygen breathing and the effect of pharmacological blockade. Acta. Med. Scand. 188: 419 (1970). 